\title{
Application of hot-stage microscopy to evaluating sample morphology changes on heating
}

\author{
Wojciech Panna $^{1} \cdot$ Piotr Wyszomirski $^{1,2} \cdot$ Piotr Kohut $^{1}$
}

Received: 13 October 2015/ Accepted: 3 February 2016/Published online: 18 February 2016

(c) The Author(s) 2016. This article is published with open access at Springerlink.com

\begin{abstract}
Investigations of the thermal properties of a raw material or a ceramic product under a hot-stage microscope allow, among others, determining the characteristic temperatures corresponding to the changes of the shape and the cross-section area of samples being heated. They are based on observing and analysing images of the sample recorded with the growth of its temperature. The pictures of changes allow establishing - for the raw materials with the ability of thermal expansion-the technological temperatures of sintering, softening, thermal expansion, melting and flowing. Their knowledge is necessary in determining optimum ranges of manufacture conditions for a number of ceramic processes. Considering some difficulties with precise determination of these characteristic temperatures and with the problem of measuring the coefficient of thermal expansion $S$ of clay raw materials, the authors have proposed hereby a new method of measuring a sample cross-section area on heating under a hot-stage microscope. It has been invented and implemented in the Matlab software environment on the basis of an image analysis of the expanding sample. The changes of its cross-section area (i.e. an outline area visible under a hot-stage microscope) are continuously recorded on the film and can be converted after digital processing into sample volume changes. The method is applicable to precise measuring the coefficient of thermal expansion $S$ of
\end{abstract}

Wojciech Panna

wojpan@agh.edu.pl

1 AGH University of Science and Technology, Mickiewicza 30, 30-059 Kraków, Poland

2 State Higher Vocational School, Mickiewicza 8, 30-100 Tarnów, Poland clay raw materials, among others those used in the manufacture of lightweight ceramic aggregates.

Keywords Hot-stage microscopy · Image analysis · Lightweight ceramic aggregates - Clay raw materials . Thermal expansion

\section{Introduction}

A hot-stage microscope was constructed by Welch in the 1950s. Using such a device it is possible to observe and record (photographic or digital recording) the changes of sample contours with temperature, which makes possible to determine fusibility (from the sample shape and geometry), and also viscosity, wettability and surface tension of various raw materials and products at the temperatures approximating the range of their melting [1, 2]. Modern hot-stage microscopes provide a continuous recording of such measurements and a computer-aided handling of laboratory data. As a method is simple, and its results are of a considerable practical significance. It has found its applicability to studying various raw materials and products as well as to solving some technological problems in the ceramic, glass and energy industries, also in metallurgy and foundry engineering.

In the manufacture of ceramics and glass, the hot-stage microscopy is used first of all to study instead the fusibility of raw materials and products, i.e. to determine instead the characteristic temperatures of softening, melting, flowing and sintering (Fig. 1) [3]. In the case of ceramic glazes, some authors also distinguish the temperatures of sphere and half-sphere that refer to the sample shapes, but do not describe physical phenomena taking place at specific temperatures $[4,5]$. Other characteristic temperatures 
(a)

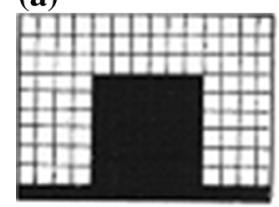

(b)

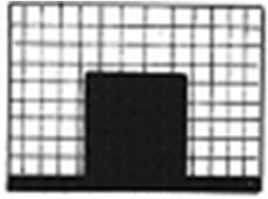

(c)

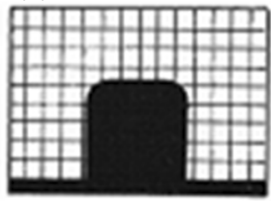

(d)

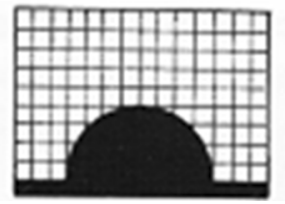

(e)

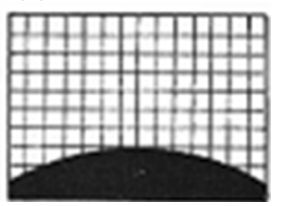

Fig. 1 Hot-stage microscope images of a sample without thermal expansion properties. Temperatures: a ambient, $\mathbf{b}$ of maximum sintering, $\mathbf{c}$ of initial softening, $\mathbf{d}$ of melting, $\mathbf{e}$ of flowing [6]

describe the behaviour of the materials that reveal thermal expansion properties; for instance, the temperature of maximum sintering is followed, among others, by the temperatures of the initial expansion and the maximum expansion (Fig. 2).

Hot-stage microscopy is also used to establish sintering curves of the material. The curve presents the dependence between the growing temperature and the ratio (expressed in \%) of heights of two samples: the initial one (prior to heating) and the sample at a given temperature of its expansion or shrinking; in ceramics it is most often used to characterize high-temperature processes of glasses or enamels, also of keramsite (LECA-lightweight expanded clay aggregates) $[2,4,7]$. Referring to the latter material, particularly useful is a method proposed in [8] and based on investigating the changes of the sample cross-section area that proceed in the course of heating and are observed under a hot-stage microscope. Respective measurements can be made either with a traditional (i.e. manual) method of the area counting under a microscope or with a specialized software that processes microscope images. A description of the latter was presented by Panna et al. [9] who adapted the Matlab software (version R2013a) and applied it to the investigations of a susceptibility of some domestic clays to thermal expansion. The current paper gives details of this procedure including an authors' own programming tool extended by necessary modifications. It makes possible the determination of the thermal expansion coefficient $S$ in the course of measurements under a hot-stage microscope. This coefficient, defined as the ratio of the sample initial volume to the sample volume at a temperature of its maximum expansion, describes a usefulness of a given raw material in the manufacture of keramsite.

\section{Description of the method}

Adequate observations under a hot-stage microscope (a device HSM type $3 \mathrm{M}$ made by the Italian company Misura was used) are recorded on a film presenting in a "frameafter-frame" manner the images of the sample when its temperature increases. Using a software that controls the hot-stage microscope, a number of the film frames assigned to a given temperature change can be chosen. The best selection is if one film frame corresponds to a temperature growth of $1 \mathrm{~K}$. To calculate diameters and volumes of objects analysed, the authors have developed and implemented image pre-processing and analysis algorithms based on the Image Processing Toolbox in the MATLAB software environment. The image analysis algorithms involve the region-oriented segmentation technique $[10,11]$ and the flow chart of the operations implemented is depicted in Fig. 3.

The image sequences were converted from the RGB to the greyscale format and processed by means of image preprocessing techniques. After binarization and filtration, an image (after the morphology opening) was ready to the stage of the image analysis proper. The image features calculated can be expressed in the form of the area (i.e. an outline visible under a microscope), contours, diameters and volume of the object analysed. The details of the method invented in the Matlab environment which makes possible determining the cross-section area and the volume of the sample in each frame of the film, and explanations of the respective commands are shown in Fig. 4.

The commands in the lines 1-4 are used to read in the film in the.avi format. The instruction loop for has been introduced to analyse the course of observations under a hot-stage microscope in a selected range of frames, where (a)

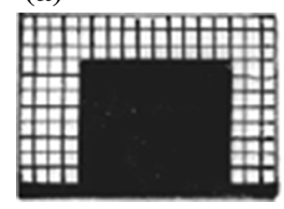

(b)

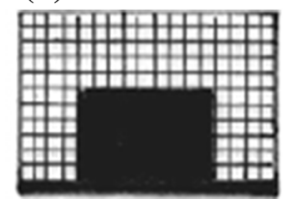

(c)

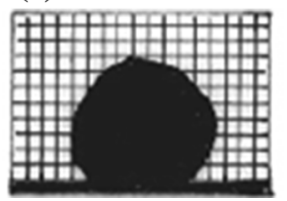

(d)

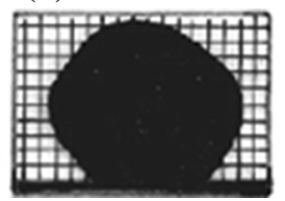

(e)

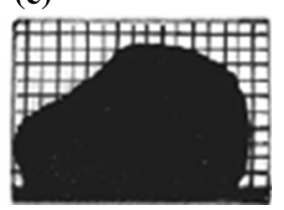

Fig. 2 Hot-stage microscope images of a raw material with thermal expansion properties. Temperatures: a ambient, $\mathbf{b}$ of maximum sintering, $\mathbf{c}$ of initial expanding, $\mathbf{d}$ of maximum expanding, $\mathbf{e}$ after maximum expanding but prior to melting [6] 
Fig. 3 Operations enclosed in the algorithms developed

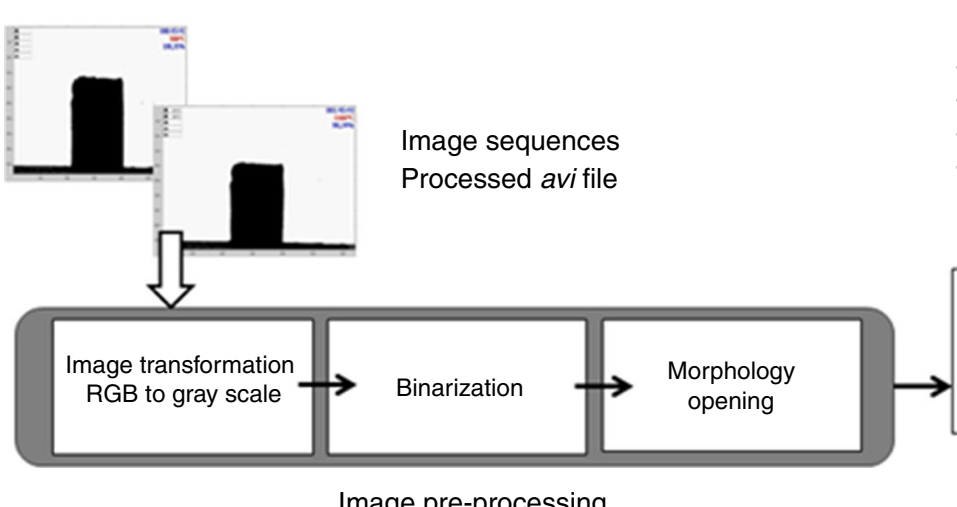

Image pre-processing calculated data:

- Cross-section area

- Contour pixels

- Diameter

- Volume

Image analysis (based on region-oriented segmentation)

Image analysis
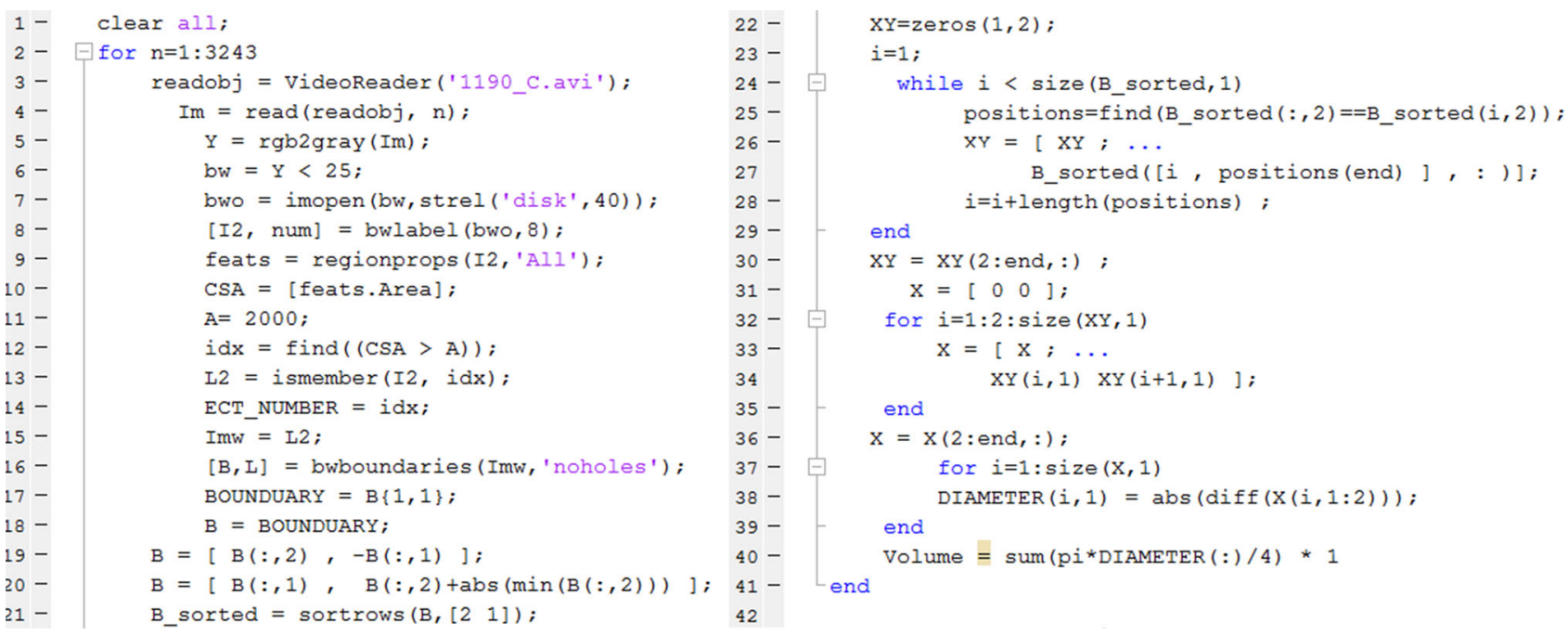

Fig. 4 Source code of the developed programming tool measuring the sample area and its volume

$n$ corresponds to the selected film frame. This range must fall within the interval $n=1 / n_{\mathrm{e}}\left(n_{\mathrm{e}}\right.$-the number of the last film frame). The statements in lines 5-16 execute image pre-processing and analysis stage. The image analysis provides image features, among others such as the crosssection area, coordinates of contour pixels and the sample diameter. Further pre-processing includes selection of an image figure with the largest area (i.e. larger than the set one). A transformation of the colour image into the monochromatic one is completed with the statement in the line 5 (Fig. 5a), while binarization with a high threshold level [12] that implements a change of the greyscale image into a binary one is executed with the statement in the line 6 (Fig. 5b, a1-an image histogram). Tiny and frayed regions of the image are removed using the morphology opening operation (line 7, Fig. 5c). Further procedures of the analysis consist of image segmentation and extraction of its features, and are performed in the lines 8 and 9, respectively. Removing the regions with the areas smaller than the area set (2000 pixels) is executed under the conditions expressed in the line 12. An exemplary result of such a filtration involving the cross-section area is presented in Fig. 5c.

The next stage, which is the processing the image features, involves the determination of sample volume changes in the course of measurements (commands in lines 17-41). It is based on selecting the positions of the envelope points of the sample geometrical figure (commands in lines 21-29) in the $X-Y$ coordinates and setting them as the rows in the matrix (two points on the $X$ axis correspond to one $Y$ position (commands in lines 30-35). These points mark out the vectors of diameters DIAMETER (commands in lines 36-39) that, finally, are used in the calculation of the sample volume (command in line 40). The volume determined is a total of the layers, each of them being a cylinder with a height equal to one pixel, contained between the base of the sample and its top. After executing the Run command, the results of the sample cross-section area and its volume measurements appear in the Matlab command window. The procedure correctness can be verified with a visualization of the process following the commands in a 


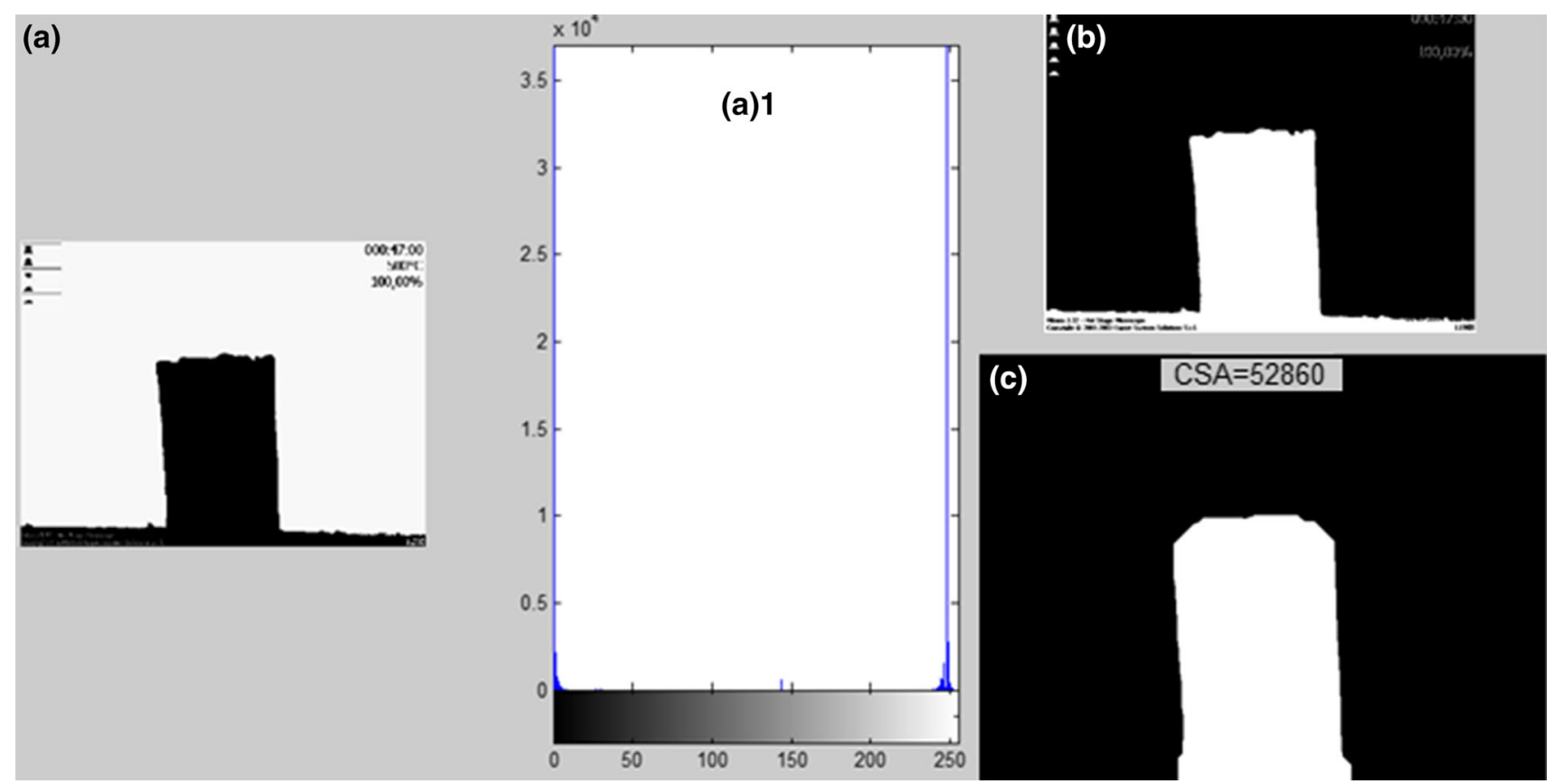

Fig. 5 Visualization of the image pre-processing and analysis. a the hot-stage microscope image presented in the greyscale, a1 the image histogram presenting the number of pixels corresponding to a given grey level $(0=$ black, $255=$ white $)$, b the image after binarization,

web page [13]. It shows the process from the stage of generating the images of sample diameters' calculation (Fig. 6a) and the 3D sample image (Fig. 6b, c). Exemplary calculations were carried out for a sample of a thermally expanding clay raw material at a temperature of its maximum expansion. c the image after morphological filtration and the analysis of the image assuming a feature in the form of the cross-section area with a number of its pixels

\section{Sample material}

A susceptibility to thermal expansion was investigated on three samples of claystones from Dylągówka (Dynów Foothills, Podkarpacie Voivodeship, SE Poland), taken from various depth of the deposit. Their significant content
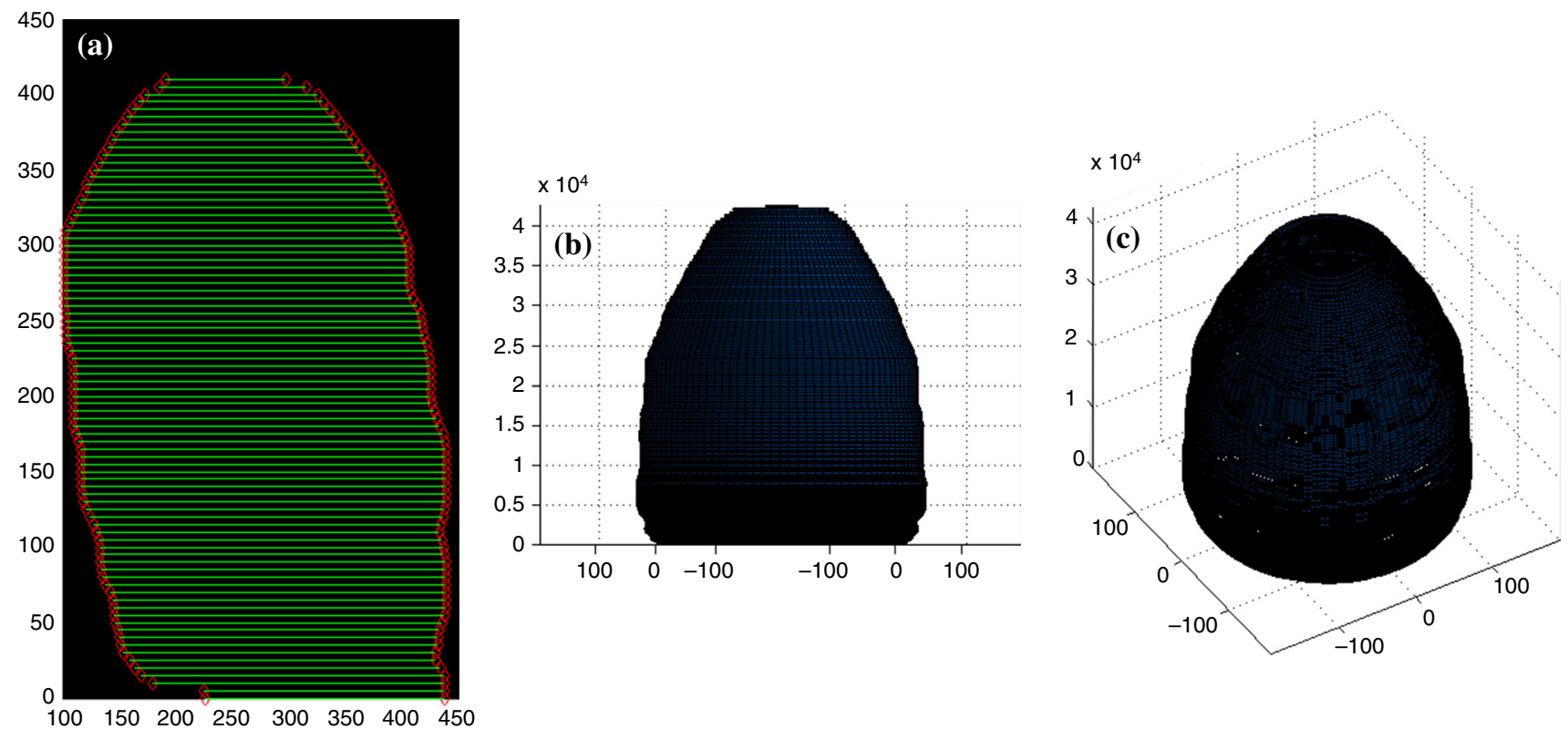

Fig. 6 Determination of the sample volume in a selected frame of the film-a visualization. a an image of counting the sample diameters; b sample visualization $-X Y$ projection, c sample visualization-a 3D sample image in $X Y Z$ projection 
Table 1 Selected parameters of the claystones from the upper (A), middle (B) and lower (C) parts of the Dylagówka deposit [15]

\begin{tabular}{|c|c|c|c|c|}
\hline \multirow[t]{2}{*}{ Sample symbol } & \multirow[t]{2}{*}{ Smectite content $/ \%$} & \multirow[t]{2}{*}{ Remaining mineral phases } & \multicolumn{2}{|c|}{ Content of grain fractions $/ \%$} \\
\hline & & & $<1 \mu \mathrm{m}$ & $<0.5 \mu \mathrm{m}$ \\
\hline A & 30 & Opal, quartz, illite, kaolinite, clinoptilolite, haematite & 52.8 & 37.3 \\
\hline B & 49 & Opal, quartz, illite, & 71.6 & 58 \\
\hline $\mathrm{C}$ & 33 & Opal, quartz, calcite, kaolinite & 42.8 & 31.5 \\
\hline
\end{tabular}

of clay minerals (smectites, illite and kaolinite) is characteristic: e.g. smectites make usually more than $30 \%$ of a rock. The first variety (sample A) collected from the uppermost part of the Dylaggówka deposit represents Lower Eocenian brick-red to brownish-red clinoptilolite-montmorillonite claystones, which occur also in other localities of the Dynów Foothills [14]. Two other varieties of the variegated shales, collected in the middle and lower parts of the deposit, are represented by bluish (sample B) and light green (sample C) and identified as the siliceousmontmorillonite claystones because of their elevated opal contents. Their detailed characteristics were given in

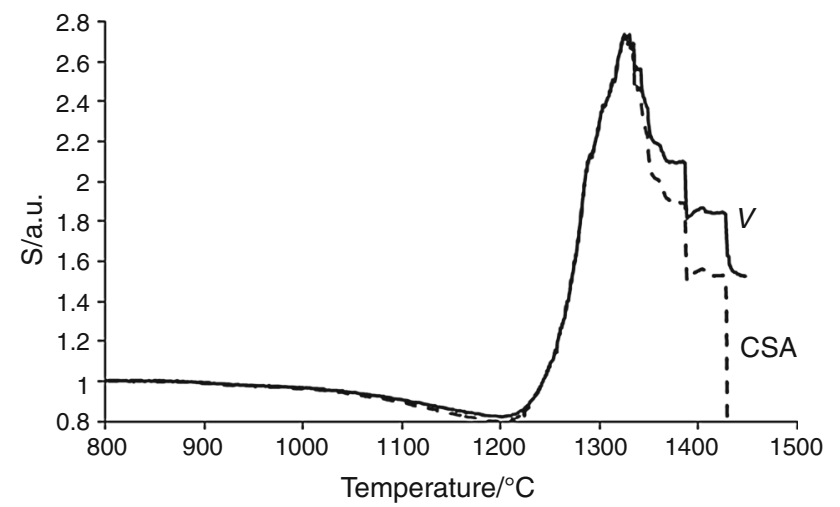

Fig. 7 Changes of the expansion coefficient $S$ values calculated from sample cross-section area (CSA) and volume $(V)$ measurements. The acid-activated sample A2 from the uppermost profile part of the Dylągówka deposit [16]
Panna et al. [15], whereas the rock parameters pertaining to the current study have been listed below (Table 1).

Test samples were prepared from the rock material disintegrated to the grains $<0.25 \mathrm{~mm}$ in the form of pellets with a diameter of about $2 \mathrm{~mm}$ and a height of about $4 \mathrm{~mm}$ using a small hand press. The measurements were carried out under a high-stage microscope HSM $3 \mathrm{M}$.

\section{Application of image analysis to the investigations of raw materials with thermal expansion properties}

When conducting investigations of raw materials, their susceptibility to expansion on heating is often expressed as the changes of the coefficient of thermal expansion $S$. The coefficient is calculated on the basis of the cross-section area changes of the solid body that is an equivalent of the sample volume at the given temperature $[8,9,16]$. The results indicate, however, considerable differences in the values of the expansion coefficient if calculated from the area and the volumetric changes (both measurements were made on the same recording film obtained during the hotstage microscope test). It is particularly expressed in the sample that assumes the spherical shape in the range of the measurement temperatures, i.e. in the course of its expansion (Fig. 7). It can be shown, among others, on the acidmodified clay-siliceous rock from Dylągówka, which is characterized by a considerable increase of the expansion coefficient values [16]. Its difference of the area- and volume-calculated coefficient values is high, reaching 0.3

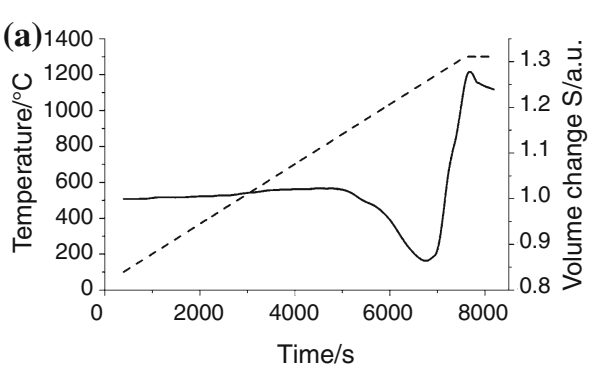

Fig. 8 Changes of the expansion coefficient $S$ (solid curve) and the temperature (dashed curve) values as the function of time, determinate from the measurements in the hot-stage microscope. Claystone
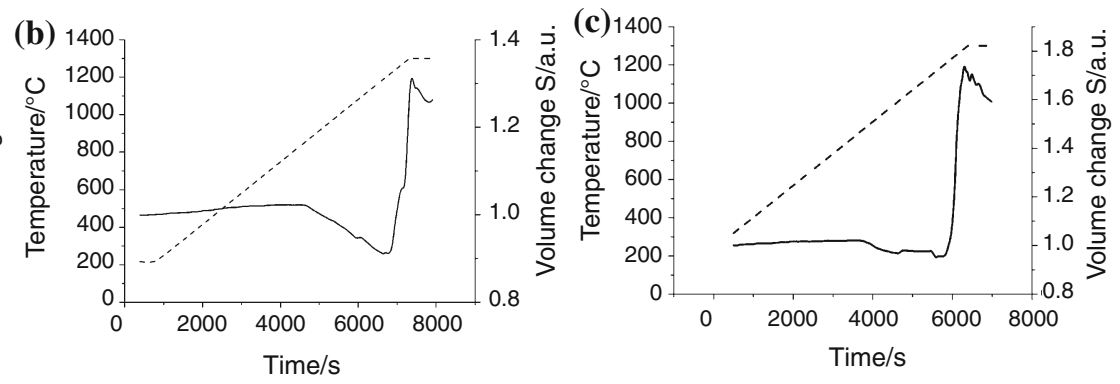

samples from the upper (a), middle (b) and lower (c) profile parts of the Dylągówka deposit 
Table 2 Expansion coefficient $S$ values measured using hot-stage microscopy (image analysis) and pycnometry (volume analysis)

\begin{tabular}{lll}
\hline Sample & \multicolumn{2}{l}{$S$ coefficient values [a.u.] based on } \\
\cline { 2 - 3 } & Digital image analysis & Volumes after firing at $1300{ }^{\circ} \mathrm{C}$ \\
\hline A & 1.23 & $1.32 \pm 0.03$ \\
B & 1.26 & $1.12 \pm 0.02$ \\
C & 1.59 & $1.56 \pm 0.04$ \\
\hline
\end{tabular}

at $1400{ }^{\circ} \mathrm{C}$, which represents a measurement error of $17 \%$. In contrary, the error is considerably low (up to $2 \%$ ) if the sample assumes on heating a shape close to cylindrical.

The applicability of the method proposed to determine values of the thermal expansion coefficient $S$ was tested on three samples of the claystones from Dylągówka. Their volumetric changes on heating were measured and compared using a hot-stage microscope Misura HSM $3 \mathrm{M}$ and a sand pycnometer GeoPyc 1360 (produced by Micrometrics). The latter tests were conducted on the samples fired at $1300{ }^{\circ} \mathrm{C}$. To minimize potential measurements errors resulting from recording the firing temperatures in a laboratory furnace that has a much bigger chamber in comparison to a heating chamber of the hot-stage microscope, the samples were heated at a rate of $10{ }^{\circ} \mathrm{C} / \mathrm{min}$ until reaching $1300{ }^{\circ} \mathrm{C}$ and next kept at this temperature for $30 \mathrm{~min}$ to stabilize their effects of thermal expansion (Fig. 8a-c). Measurement of the volume received in the sand pycnometer was performed on four samples of each of the raw materials. The result is shown as an average of these measures and as precision accepted the standard deviation.

The values of the coefficient $S$ obtained as a result of firing the samples in the laboratory furnace are comparable to those obtained with the hot-stage microscopy (Fig. 8a-c, Table 2). Small discrepancies may have been caused, among others, by differences of the temperatures recorded with two various devices, and also some inaccuracies of the volume measurements in both the digital image analysis and sand pycnometry. As the results obtained by authors method correlate with those pycnometry ones, it should be recognized that the hot-stage microscopy is an applicable and useful method to the studies of the changes of the clay raw materials with thermal expansion properties.

\section{Conclusions}

The authors used the images obtained under a hot-stage microscope to the determination of sample changes on heating. It was accomplished applying the Matlab software to counting up the cross-section (i.e. the outline) of the solid body that represents the sample at a given temperature and calculating then the sample volume from the area measured. It has been demonstrated that the method is particularly useful for the samples of clay raw materials with thermal expansion properties. The advantageous is minimizing the errors in the determining the coefficient of thermal expansion $S$ that result mainly from changes of sample geometry, when the sample assumes a shape approximating the sphere. The errors are significantly lower when the sample has a form of a cylinder at lower temperatures.

The differences of the $S$ coefficient values measured using hot-stage microscopy and sand pycnometry are insignificant in the claystones from Dylągówka treated at $1300{ }^{\circ} \mathrm{C}$. It is a proof that the HSM computer-supported method of image analysis proposed by the authors is a valuable research tool applicable to studying thermal expansion phenomena.

Acknowledgements This study was carried out within the AGH University of Science and Technology (Kraków), Grant Number 15.11.160.746.

Open Access This article is distributed under the terms of the Creative Commons Attribution 4.0 International License (http://creative commons.org/licenses/by/4.0/), which permits unrestricted use, distribution, and reproduction in any medium, provided you give appropriate credit to the original author(s) and the source, provide a link to the Creative Commons license, and indicate if changes were made.

\section{References}

1. Garcia-Valles M, Hafes HS, Cruz-Matías I, Vergés E, Aly MH, Nogués J, Ayala D, Martínez S. Calculation of viscosity-temperature curves for glass obtained from four wastewater treatment plants in Egypt. J Therm Anal Calorim. 2013;111:107-14.

2. Stábile FM, Piccico M, Serra MF, Rafti M, Súarez G, Rendtorff NM. Viscosity and thermal evolution of density and wetting angle of a commercial glaze by means of hot stage microscopy. Proced Mater Sci. 2015;9:563-70.

3. DIN 51730. Determination of fusibility of fuel ash. German Standard 1984

4. Dumitrache RL, Teoreanu I. Melting behaviour of feldspar porcelain glazes. UPB Sci Bull Ser B. 2006;68(1):3-16.

5. Ozturk ZB. Thermal behavior of transparent wall tile glazes containing ulexite. J Aust Ceram Soc. 2015;51(2):69-74.

6. Wyszomirski P, Galos K. Mineral and chemical raw materials of ceramic industry. Kraków: Wyd. AGH; 2007 (in Polish).

7. Aineto M, Acosta A, Rincón JM, Romero M (2005) Production of lightweight aggregates from coal gasification fly ash and slag. 2005 world of coal ash, April 11-15, 2005, Lexington, Kentucky USA.

8. Suwak R. Application of high-temperature microscope to tests the behaviour of dust and sludge from the process gases. Sci Works Inst Ceram Constr Mater. 2011;7:67-78 (in Polish).

9. Panna W, Wyszomirski P, Gasek K, Dudek R, Łabuz A. Hot stage microscopy in determining the suitability of selected clay rocks from south-eastern Poland to manufacture lightweight aggregates. Cem Wapno Beton. 2015;20(2):79-87.

10. Kohut P. Mechatronics systems supported by vision techniques. Solid State Phenom. 2013;196:62-73. 
11. Jahne B. Digital image processing: concepts, algorithms, and scientific application. Berlin: Springer; 1995.

12. Tadeusiewicz R, Korohoda P. Computer analysis and image processing. Kraków: Progress of Telecomunication Foundation Publishing House; 1997 (in Polish).

13. http://kcimo.pl/pl/pobieranie/604.

14. Bajda T, Franus W, Manecki A, Manecki M, Mozgawa W, Sikora M. Sorption of heavy metals on natural zeolite and smectitezeolite shale from the Polish Flysh Carpathians. Pol J Environ Stud. 2004;13(3):7-10.
15. Panna W, Wyszomirski P, Myszka R. Characteristics of the clayey-siliceous rock from the "Dylągówka-Zapady" deposit (Polish Flysh Carpathians) as a mineral raw material. Gospodarka Surowcami Mineralnymi-Miner Resour Manag. 2014;30(2): 85-102 (in Polish).

16. Panna W, Szumera M, Wyszomirski P. The impact of modifications of the smectite-bearing raw materials on their thermal expansion ability. J Therm Anal Calorim. 2016;123(2): $1153-1161$. 